\title{
How can vulnerable groups be recruited to participate in a community-based smoking cessation program and perceptions of effective elements: A qualitative study among participants and professionals
}

\author{
Barbara van Straaten', Gert-Jan Meerkerk', Floor A. van den Brand'², Pamela Lucas ${ }^{3}$, Nienke de Wit', Gera E. Nagelhout ${ }^{1,5}$
}

\begin{abstract}
INTRODUCTION Smokers from vulnerable groups, such as smokers with a low socioeconomic position, often have more difficulty quitting smoking and often are more difficult to recruit for smoking cessation programs. It is important to know how vulnerable groups can be recruited and motivated to participate in a smoking cessation program and what participants and professionals perceive as effective elements.

METHODS Qualitative interviews were performed with participants of a communitybased smoking cessation program in the Netherlands $(n=18)$ and professionals involved in the recruitment of participants or as trainers in the community-based smoking cessation program $(n=8)$. They were interviewed twice: once before the program had started and once after the program had ended. Interviews were semi-structured and conducted between September 2018 and February 2019. RESULTS We found that organizing the program in the neighborhood lowered the threshold to participate, that registration should be quick and easy, that an active approach is needed, and that personal contact is important. This study also showed that information sharing, social support, commitment of the trainer, and personal contact are perceived as effective elements of such a program.

CONCLUSIONS This study shows that vulnerable smokers can be successfully recruited for a smoking cessation program. We recommend that such interventions include a group setting, extensive personal contact between participants and a committed trainer, and implementation of the program at a location in the neighborhood of the target group. Practical recommendations for professionals are to personally approach people multiple times if needed, to make sure that registration is quick and easy, and to fill in the registration form immediately during recruitment.
\end{abstract}

AFFILIATION

1 IVO Research Institute, The Hague, the Netherlands 2 Department of Family Medicine, Maastricht University (CAPHRI), Maastricht, the Netherlands 3 Amsterdam Research Institute for Societal Innovation, Research group Urban Social Work/ Research group Poverty Interventions Amsterdam University of Applied Sciences,

Amsterdam, the Netherlands 4 IDEM Rotterdam, Rotterdam, the Netherlands

5 Department of Health Promotion, Maastricht University (CAPHRI),

Maastricht, the Netherlands

CORRESPONDENCE TO

Barbara van Straaten. IVO Research Institute, PO Box 30833, 2500 GV, The Hague, the Netherlands. E-mail: straaten@ivo.nl

\section{KEYWORDS}

qualitative research, smoking cessation, vulnerable groups, social class, community-based program

Received: 20 April 2020 Revised: 30 September 2020

Accepted: 8 October 2020

\section{INTRODUCTION}

People who want to quit smoking can benefit from professional help and a group setting in which people quit smoking together ${ }^{1}$. Vulnerable smokers, such as smokers with a low socioeconomic position or smokers with mental health problems, often find it more difficult quit smoking ${ }^{2-7}$. This could be for several reasons: vulnerable smokers have a stronger nicotine addiction, have more people in their social environment who smoke, receive less social support to quit, are less likely to complete behavioral support or pharmacotherapy, have a lower level of self-efficacy for quitting, have more life stressors, or have more financial barriers for paid professional help $p^{4,8-10}$. 
Intensive community-based smoking cessation programs, specifically targeted at vulnerable smokers and including behavioral and pharmacological support, may help vulnerable smokers to quit smoking ${ }^{8,11}$.

Programs that are not specifically targeted at vulnerable smokers are often mostly effective in reaching more advantaged groups ${ }^{12}$. Programs targeted at vulnerable smokers often find it difficult to effectively recruit the target group ${ }^{11,13}$. Special attention is therefore needed to recruit vulnerable smokers. Some previous studies have examined which groups participate in smoking cessation programs more than others ${ }^{14,15}$, what are the barriers for participation ${ }^{16,17}$, and which recruitment strategies are effective for self-help or clinical smoking cessation interventions ${ }^{18,19}$. However, studies about effective recruitment strategies for community-based programs geared towards vulnerable groups are lacking. In addition, many studies examined completion or continued participation in programs among people who already signed up for the program, rather than how to recruit and motivate vulnerable smokers to sign up in the first place.

Besides an effective recruitment strategy to reach vulnerable smokers for community-based smoking cessation programs, it is important to know which elements of these programs are especially effective for vulnerable smokers. There are indications that such programs should be located in the local community setting, provide intensive professional support and coaching (also in-between sessions), pay much attention to social support, include pharmacotherapy, remove financial barriers and be tailored to cultural values and beliefs ${ }^{4,10,20}$. Few programs have combined these elements ${ }^{10}$ and it is therefore unknown which elements are especially important for vulnerable smokers.

The current qualitative study aims to evaluate the recruitment for a community-based smoking cessation program for vulnerable smokers in two cities in the Netherlands, The Hague and Utrecht, by interviewing participants and professionals that were involved in the program. Our research questions were: 1) how can vulnerable smokers be recruited and motivated to participate in a community-based smoking cessation program, and 2) what do participants and professionals perceive as the effective elements of this smoking cessation program?

\section{METHODS}

\section{Design}

Participants and professionals involved in the recruitment of participants or as trainers in the community-based smoking cessation program were interviewed twice: once before the program had started and once after the program had ended. Interviews were semi-structured and conducted between September 2018 and February 2019.

\section{Sample}

The smoking cessation program was developed and implemented by the mental healthcare institute Indigo in The Hague and the addiction care institute Jellinek in Utrecht, in the Netherlands. The program aimed at recruiting vulnerable smokers from two neighborhoods with relatively high numbers of vulnerable inhabitants: Escamp in The Hague, and Hoograven in Utrecht. Specifically, the recruitment was aimed at smokers aged $\geq 18$ years, who were vulnerable due to having minimal education, being unemployed, having a long-term illness and/or having social or mental health problems. A high motivation to quit smoking was not a precondition for participation in the smoking cessation program.

After people were recruited to take part in the smoking cessation program, 10 participants from each neighborhood were selected to be interviewed. Participants were selected in such a way that the sample represented the various cultural backgrounds and the gender composition of the group that attended the smoking cessation program. After the interviews, 2 participants were excluded from the analyses because they appeared not to have a low socioeconomic position or mental health problems. The interviews of 18 participants were used for analyses. At follow-up, 17 (94\%) of these participants could be reached for a second interview. Additionally, professionals who did the recruitment, and/or led the smoking cessation program, were interviewed before $(n=7)$ and after $(n=5)$ the program had finished. In total, 8 professionals were interviewed.

\section{Smoking cessation program}

The community-based smoking cessation program 
that was offered to the participants in Utrecht was based on the group training 'Rookvrij! Ook jij?' (Smoke-free! You too?) developed by SineFuma, a commercial company specialized in organizing and facilitating smoking cessation interventions ${ }^{21}$. The community-based smoking cessation program that was offered to the participants in The Hague was based on the group training 'Voel je vrij!' (Feel free!) developed by Momentum Training \& Coaching ${ }^{26}$. These smoking cessation programs are typically administered to groups of around 10 people by qualified professional stop-smoking coaches and consists of seven weekly sessions of 90 minutes each. The first two sessions are meant to prepare participants for their quit attempt and give information about pharmacological support. At the start of the third session, the group quits smoking together. The remaining four sessions are meant to help participants through the first month of quitting smoking. Participants get information about withdrawal symptoms, tips on how to handle them, and social support from the group.

Three extra sessions were added to the smoking cessation programs to extend the support of the participants. In the first extra starting session participants received more detailed information about the program and could ask questions before starting with the program. The second extra session was implemented halfway through the program and did not focus on smoking cessation but on health in general. The third extra session, two months after the program had ended, was a festive follow-up session. The smoking cessation program evaluated in this paper therefore consisted of 9 weekly sessions of 90 minutes each, and one follow-up session after two months. Participants were also offered, when appropriate, (a referral for) help with other issues, such as mental health or financial problems. Complementarily, a WhatsApp group was set up to enable easy contact with the other participants for extra support and a 'buddy element' in which a participant was linked to one other participant who could be contacted in difficult times.

The smoking cessation program was entirely free for participants, including the use of pharmacological support. In Utrecht, the program was given by smoking cessation coaches from SineFuma and located in a community center. In The Hague, the program was given by smoking cessation coaches from Indigo Haaglanden, the local mental healthcare provider, and located in a mosque, a health center and a community center.

\section{Data collection}

All participants in the smoking cessation program received a questionnaire before the start of the program. Data from this baseline questionnaire were used to describe the sample (Table 1). This questionnaire was part of a quantitative study on this smoking cessation program ${ }^{25}$. Participants and professionals signed informed consent forms. The interviews were conducted by experienced interviewers. Participants received $€ 15$ as reimbursement for the first and $€ 20$ for the second interview.

Table 1. Characteristics of participants in the smoking cessation program who were interviewed $(\mathbf{N}=18)$

\begin{tabular}{|c|c|c|}
\hline Characteristics & $\begin{array}{c}\text { The Hague } \\
n(\%)\end{array}$ & $\begin{array}{l}\text { Utrecht } \\
n(\%)\end{array}$ \\
\hline \multicolumn{3}{|l|}{ Gender } \\
\hline Men & $4(44.4)$ & $2(22.2)$ \\
\hline Women & $5(55.6)$ & $7(77.8)$ \\
\hline \multicolumn{3}{|l|}{ Age (years) } \\
\hline $37-49$ & $2(22.2)$ & $2(22.2)$ \\
\hline $50-59$ & $2(22.2)$ & $5(55.6)$ \\
\hline$\geq 60$ & $5(55.6)$ & $2(22.2)$ \\
\hline \multicolumn{3}{|l|}{ Education level } \\
\hline Primary education & $3(33.3)$ & $2(22.2)$ \\
\hline Lower pre-vocational secondary & $1(11.1)$ & $0(0.0)$ \\
\hline Middle pre-vocational secondary & $3(33.3)$ & $3(33.3)$ \\
\hline Secondary vocational & $2(22.2)$ & $2(22.2)$ \\
\hline $\begin{array}{l}\text { Senior general secondary and pre- } \\
\text { university }\end{array}$ & $0(0.0)$ & $1(11.1)$ \\
\hline $\begin{array}{l}\text { Higher professional and university } \\
\text { Bachelor's or Master's }\end{array}$ & $0(0.0)$ & $1(11.1)$ \\
\hline \multicolumn{3}{|l|}{ Employment situation } \\
\hline Employed & $4(44.4)$ & $1(11.1)$ \\
\hline Receiving benefits & $5(55.6)$ & $6(66.7)$ \\
\hline Retired & $0(0.0)$ & $2(22.2)$ \\
\hline \multicolumn{3}{|l|}{ Living situation } \\
\hline Alone & $5(55.6)$ & $5(55.6)$ \\
\hline With partner & $2(22.2)$ & $1(11.1)$ \\
\hline With child(ren) & $1(11.1)$ & $1(11.1)$ \\
\hline With partner and child(ren) & $1(11.1)$ & $2(22.2)$ \\
\hline
\end{tabular}


Table 1. Continued

\begin{tabular}{|c|c|c|}
\hline Characteristics & $\begin{array}{c}\text { The Hague } \\
n(\%)\end{array}$ & $\begin{array}{l}\text { Utrecht } \\
n(\%)\end{array}$ \\
\hline \multicolumn{3}{|l|}{ Country of birth } \\
\hline The Netherlands & $3(33.3)$ & $8(88.9)$ \\
\hline Suriname & $3(33.3)$ & $1(11.1)$ \\
\hline Morocco & $1(11.1)$ & $0(0.0)$ \\
\hline Curacao & $1(11.1)$ & $0(0.0)$ \\
\hline Somalia & $1(11.1)$ & $0(0.0)$ \\
\hline \multicolumn{3}{|l|}{ Parents' country of birth } \\
\hline Both parents born in the Netherlands & $2(22.2)$ & 7 (77.8) \\
\hline One parent born in the Netherlands & $0(0.0)$ & $1(11.1)$ \\
\hline $\begin{array}{l}\text { Both parents born outside the } \\
\text { Netherlands }\end{array}$ & 7 (77.8) & $1(11.1)$ \\
\hline \multicolumn{3}{|l|}{ Receiving care or help } \\
\hline No care or help & $5(55.6)$ & $1(11.1)$ \\
\hline Psychological help & $1(11.1)$ & $2(22.2)$ \\
\hline Medical help & $0(0.0)$ & $3(33.3)$ \\
\hline $\begin{array}{l}\text { Other help or multiple sources of care } \\
\text { or help }\end{array}$ & $3(33.3)$ & $3(33.3)$ \\
\hline $\begin{array}{l}\text { Cigarettes per day before group } \\
\text { training*, mean } \pm \text { SD }\end{array}$ & $13.6 \pm 6.5$ & $24.1 \pm 12.8$ \\
\hline \multicolumn{3}{|l|}{ Quit smoking during group training } \\
\hline Quit smoking & $2(22.2)$ & $6(66.7)$ \\
\hline Tried to quit, but smoking again & $3(33.3)$ & $2(22.2)$ \\
\hline Did not try to quit & $4(44.4)$ & $0(0.0)$ \\
\hline Lost to follow-up & $0(0.0)$ & $1(11.1)$ \\
\hline
\end{tabular}

${ }^{*} n=16$; one participant from The Hague and one from Utrecht did not smoke daily before the group training.

The first interview with the participants focused on how they came to participate in the program: who had contacted them, in what way, what convinced them to participate, what were their reasons to participate and what did they expect from the program. Professionals were asked how recruitment took place, what their own role was, and what they believed worked in recruiting people. The first interview lasted on average 26 minutes for participants (range: 14-40 minutes) and 34 minutes for professionals (range: 19-59 minutes).

The second interview focused on the effective elements of the program as perceived by the interviewees. Participants were asked about their experiences with the program, what they thought about quitting in a group, what they liked and disliked about the program, what they thought about the information that they had received, and whether they could connect well with the trainer. Professionals were asked to describe the program and the sessions, what they thought participants liked and disliked about the program, and what they thought were success factors of the program. The second interview lasted on average 26 minutes for participants (range: 8-56 minutes) and 51 minutes for the professionals (range: 36-74 minutes).

\section{Analysis}

All interviews were audio-recorded and transcribed. Analyses were done thematically using NVivo version 12. Three authors who performed the analyses read all transcripts of the interviews to familiarize themselves with the data. Two independently coded six transcripts in the first round of coding, using open inductive coding. They compared their codes and reached consensus concerning an initial coding framework. In the second round of coding, another six transcripts were independently coded using the coding framework and final adjustments to the coding framework were made. Codes with the lowest agreement between coders were discussed between the two coders until consensus was reached. Following this, one examined the coding framework and made suggestions for changes in consultation with another coder. This yielded a selection of seven main structuring codes, with several subcategories for each code. All transcripts were coded independently using this coding framework. Again, disagreements between codes were discussed until consensus was reached. No new main structuring codes emerged after coding a selection of 12 interviews, thus reaching saturation. We summarized the main codes and subcategories for the total group. Subsequently, we explored differences regarding gender and smoking status after the program.

\section{RESULTS}

\section{Recruitment strategies}

Most participants from Utrecht were recruited via their general practice and most participants from The Hague were recruited via the mosque they regularly visited, where one of the prevention workers was working. Others were recruited by their dietician, physiotherapist, personal coach, family member, or neighbor, or via Facebook. Participants who were 
recruited by the prevention worker at the mosque, often knew them well because of their visits to the mosque. They were recruited by the prevention worker in an informal and accessible way.

'... we have known each other for a long time. So in between ... you speak to someone and eh ... about this, he talked to me separately and just showed the advantages and disadvantages of it ... and then I thought, well, it's worth trying.' (Participant, male, aged 65 years, The Hague)

For some participants, the already existing relation between them and the prevention worker, seems to have promoted a feeling of trust and thereby participation in this intervention. Directly after a participant agreed to take part in the program, a registration form was filled in by the care professional or by the participant via a special website. After registration, a prevention worker from the program contacted the participant to provide further information about the program. Participants appreciated the first contact with the professionals and had positive expectations of the intervention, which contributed to their motivation to participate.

The professionals who were interviewed about ways to effectively recruit vulnerable smokers that were applied in the community-based smoking cessation program, referred to the benefits of easy registering via a website:

'You enter your name and you press ok, and it's done.' (Professional, Utrecht)

Furthermore, they stressed the importance of the active, personal, and persuasive recruitment strategy, if necessary multiple times:

'Just call them even if they do not want to [participate, red.] or they are unsure. You really have to put energy into it.' (Professional, The Hague)

This strategy appeared more effective than posters and flyers. It also appeared important to recruit in places that the target group regularly visits and to complete the registration form immediately during the recruitment. Just handing over a registration form appeared not to yield good results:

'Such a form does not return and neither does the participant.' (Professional, The Hague)

A final aspect judged to be important by the professionals, was the organization of the cessation program in the neighborhood, lowering the threshold to participate:
'People prefer, especially the elderly, everything close by ... yes you notice that they also ask: is it here? Is it nearby? Then they come.' (Professional, The Hague)

According to the professionals this is especially important for vulnerable groups:

'The highly educated have less problems with that ... they can take the car, or the train or the tram. But for the other groups it is really a trip here. And for some their world consists of their neighborhood, that is their world. So if you say come outside of that neighborhood, that is an extra threshold.' (Professional, The Hague)

\section{Effective elements of the intervention}

Almost all participants (17/18) valued the specific advantages of quitting smoking in a group. It was the most commonly cited element that they perceived as effective. This was the case for those participants who stopped smoking during the intervention and for those who did not. Already in the first interview, participants expressed positive expectations about this element of the intervention:

'I think you can achieve more in a group than on your own.' (Participant, male, aged 57 years, Utrecht).

They expected motivating effects of sharing experiences and getting advice from peers, and of learning from and supporting each other. These expectations were confirmed in the interviews after the intervention. The support offered by the group members $(13 / 18)$, and the possibility to share and exchange experiences with other members of the group (14/18), were mentioned as elements that contributed to the effectiveness of the intervention:

'I liked that it was in a group, that you have support from - fellow sufferers sounds a bit heavy, but ... just people in the same situation ... just makes it easier, I think. You get tips from each other and you are supported ... That is different from following an online program on your own in front of your computer.' (Participant, female, aged 55 years, Utrecht)

With respect to gender differences, the element of sharing experiences was mentioned by men as well as women. However, the element of receiving support from the group was reported mostly by the women. Participants also thought that the composition of the group ( $7 / 18)$, consisting mainly of people from their own neighborhood, had helped them:

'Because they all come from here ... That you 
suddenly have the feeling, I live in a kind of village with people who have also stopped and who know that I have stopped, so that helps ... So I really had the idea there are a lot of people who know now, I have quit, so I really can't be seen smoking outside.' (Participant, female, aged 55 years, Utrecht)

Also, some liked the fact that they got to know more people from their neighborhood. The benefits of a group consisting of people from their neighborhood was only mentioned by women.

The professionals regarded the group setting of the program as one of the most effective elements of the intervention. They referred to both the possibility to share and exchange experiences, as well as the support participants were giving to each other:

'Yes, and they [people of vulnerable groups] are therefore sometimes less creative in coming up with solutions in the sense of: "what could I do?" And they benefit greatly from examples they hear from others, like "what did you do" and "oh I didn't think about that at all". So they can write that down and they can start applying it and try it. And it is encouraging to hear that others are taking steps, while you may not be that far yet and you think "that other person can do it, then I can do it too!".' (Professional, The Hague)

Another commonly cited element (16/18) that participants perceived as effective was the information on the health risks of smoking provided by the trainer, even though most of this information was not new to them:

'If you hear how actually damaging... smoking and what is in tobacco, you know ... you don't like that in the beginning of course because ... you smoke ... you are a smoker, ... you know that is it bad ... in the back of your mind. But you don't think about it.' (Participant, male, aged 40 years, The Hague).

This information enhanced the motivation to quit. Other information provided by the trainer dealt with the addictive properties of tobacco that make it difficult to quit smoking. The trainer provided the participants with tips and tricks on how to deal with the craving for a cigarette, such as searching for distraction when confronted with craving. These tools gave them the feeling that they could actually quit smoking. The factual information about smoking, was particularly mentioned by men from The Hague. One participant said that this information was the part of the intervention 'that has stuck with the most' (Participant, aged 65 years, The Hague).

The professionals who were interviewed also recognized the importance of providing information:

'... people liked all the themes we had ... For example about addiction, how that works. That just gives a lot of insight. That they really come to understand "gee! it is really an addiction" and "hey, it really has to do with those substances that go to your brain and what happens to you and your body".' (Professional, The Hague)

In the eyes of many participants (14/18), the trainer was an important motivator of cessation success by encouraging them to not give up. This was especially true when the trainer was a smoker and had given up smoking. That gave the participants the idea that the trainer really knew what he or she was talking about. A man from The Hague mentioned that he liked the fact that one of the trainers was of Surinamese descent, just like himself. Other aspects that were appreciated were the easiness of contacting and talking to the trainer ('I can talk to her like a friend', Participant, aged 41 years, The Hague), and the decisiveness and firmness of the trainer that helped to continue their effort in difficult times:

'She [the trainer] is doing very well ... And also like: "Come on!" Because I also had a certain point, where I thought: "Well, I give up", and I had smoked a cigarette then too. She said "Well come on, hold on, you know what you are doing it for!".' (Participant, female, aged 75 years, Utrecht).

These aspects were the basis for what some called 'the safe and open atmosphere' during the training.

The professionals also stressed the importance of the commitment of the trainer and the personal contact between the trainer and the participants with an eye for individual aspects:

'I still think that personal contact, I mean that you really need to get on top of it. That everyone has individual needs, personal needs. And the more contact you have with a participant, the greater the chance that he will stop [smoking, red]. If you remain distant and just run your program, then I'm afraid that you will be less successful. People need to feel personally addressed ...' (Professional, The Hague)

Other aspects that were mentioned as important by the participants were: the possibility to use (free) medication (Champix) (6/18), and the measurement 
of exhaled carbon dioxide to prove that the participant did not smoke $(5 / 18)$. They found the measurements motivating because it made the effects of quitting smoking visible. In addition, they enjoyed being able to prove to the group that they did not smoke, by participants who stopped smoking during the intervention and those who did not mentioned this. Finally, a few participants mentioned the WhatsApp group that enabled easy contact with the other participants for extra support, and the 'buddy element' of the program.

\section{DISCUSSION}

In this interview study, we examined how vulnerable groups can be recruited and motivated to participate in a community-based smoking cessation program and what participants and professionals perceived as the effective elements of such a program. Our interviews with participants and professionals show that an active approach is needed with frequent, intense, personal and informal contact, and that registration should be quick and easy. People may need to be approached multiple times, and recruitment should be done at places that the target group already regularly visits to effectively recruit people from a low socioeconomic position for a smoking cessation intervention. Participation seems to be enhanced by the fact that participants already had a good relationship with the recruiter (e.g. a prevention worker they know from the mosque). The program should be organized in the neighborhood, and the registration form should be filled in directly during recruitment. The effective elements of the program that were mentioned by both participants and professionals were: sharing information on the negative health impact of smoking and ways to deal with craving, support from the group, sharing experiences with the group, the commitment of the trainer, and the personal contact between the trainer and the participants. Also, it is noteworthy that only a minority of the participants used medication in addition to the program. Those participants mentioned this was one of the important elements.

When exploring gender differences and differences with respect to smoking status at the end of the program to get a better contextual picture, we found that on many of the elements the participants mentioned as effective there were no notable differences between those who quit smoking at the end of the program and those who did not. However, there were some gender differences: the benefits of a group consisting of people from your neighborhood and receiving support from the group were only or mostly mentioned by women. The factual information about smoking, was particularly mentioned by men as an effective element.

Our results are in line with previous research among vulnerable groups. Previous research has also reported on the importance of using a personal and proactive recruitment approach ${ }^{10}$ and providing smoking cessation programs in an accessible local community setting ${ }^{10,20}$. Lack of trust in healthcare professionals can be an issue especially with people from a lower socioeconomic position ${ }^{23}$. It was in line with these findings that participants were explicitly positive about a prevention worker they already knew and trusted.

Effective elements of smoking cessation programs that have also been found in previous research, are strategies to cope with craving $\mathrm{s}^{22}$, support from the group ${ }^{10,22}$, commitment of the trainer ${ }^{20}$, and the personal contact between the trainer and the participants ${ }^{20}$. Also, the effectiveness of the combination of behavioral support and medication, which was also offered in this program, was demonstrated in previous studies ${ }^{24}$. The program was entirely free for the participants. It was striking that this aspect was hardly mentioned by the participants. It might have been self-evident for the participants, and therefore not experienced as an important aspect. Other studies have shown that removing financial barriers is important to reach vulnerable groups ${ }^{10}$. It was also notable that the participants were overall very positive about this intervention, including the participants who did not quit smoking after the intervention. It can be seen as a positive aspect of this intervention that even if the 'result' was not what the participants hoped for (quitting smoking), they were still positive about the experience. We found some gender differences with regard to how the participants appreciated the elements of the program. It would be interesting to investigate this more in depth and quantitatively in future studies on smoking cessation interventions in order to develop and evaluate gender-sensitive interventions. We summarize the key points of our study:

- This study showed that vulnerable smokers can 
be successfully recruited for a smoking cessation program;

- Our study adds to previous literature by detailing how vulnerable groups can be reached and motivated to participate in a smoking cessation program;

- For effective recruitment an active approach with personal and informal contact is needed, registration should be quick and easy and the program should be organized in the neighborhood of the participants; and

- Social support, information sharing, commitment of the trainer, and personal contact are perceived by participants and professionals as effective elements of such a program.

\section{Limitations}

A limitation of this study was that we did not take into account differences in the implementation of the intervention between the two cities and between trainers. However, by focusing on the main elements that were the same for both locations, we have revealed the most relevant aspects of the intervention. Another limitation was that there may have been a self-selection bias among participants who were willing to participate in the interviews. Also, we did not ask non-participants about the barriers to recruitment and participation in the program.

\section{CONCLUSIONS}

Our study adds to previous literature by detailing how vulnerable groups can be reached and motivated to sign up for a smoking cessation program, while previous studies have mainly examined completion or continued participation among people who already signed up for such a program. Our qualitative study of what works in the recruitment of vulnerable smokers, may serve as a starting point for the development of recruitment strategies for vulnerable smokers for future targeted smoking cessation interventions. We recommend that such interventions include a group setting, extensive personal contact between participants and a committed trainer, and implementation of the program at a location in the neighborhood of the target group.

\section{REFERENCES}

1. Stead LF, Carroll AJ, Lancaster T. Group behaviour therapy programmes for smoking cessation. Cochrane Database Syst Rev. 2017;3(3):CD001007. doi:10.1002/14651858.CD001007.pub3

2. Brathwaite R, Smeeth L, Addo J, et al. Ethnic differences in current smoking and former smoking in the Netherlands and the contribution of socioeconomic factors: a crosssectional analysis of the HELIUS study. BMJ Open. 2017;7(7):e016041. doi:10.1136/bmjopen-2017-016041

3. Erdem Ö, Riva E, Prins RG, Burdorf A, Van der Doef M. Health-related behaviours mediate the relation between ethnicity and (mental) health in the Netherlands. Ethn Health. 2019;24(3):287-300. doi:10.1080/13557858.2017.1346181

4. Hiscock R, Bauld L, Amos A, Fidler JA, Munafò M. Socioeconomic status and smoking: a review. Ann N Y Acad Sci. 2012;1248:107-123. doi:10.1111/j.1749-6632.2011.06202.x

5. Kotz D, West R. Explaining the social gradient in smoking cessation: It's not in the trying, but in the succeeding. Tob Control. 2009;18(1):43-46. doi:10.1136/tc.2008.025981

6. McNeill A. Smoking and mental health: A review of the literature. In: Symposium report: Smoking and mental health. http://citeseerx.ist.psu.edu/viewdoc/ download?doi=10.1.1.622.6748\&rep=rep1\&type=pdf. Accessed September 30, 2020.

7. Weinberger AH, Mazure CM, Morlett A, McKee SA. Two decades of smoking cessation treatment research on smokers with depression: 1990-2010. Nicotine Tob Res. 2013;15(6):1014-1031. doi:10.1093/ntr/nts213

8. Brown T, Platt S, Amos A. Equity impact of European individual-level smoking cessation interventions to reduce smoking in adults: a systematic review. Eur J Public Health. 2014;24(4):551-556. doi:10.1093/eurpub/cku065

9. Nagelhout G, Hogeling L, Spruijt R, Postma N, de Vries H. Barriers and facilitators for health behavior change among adults from multi-problem households: a qualitative study. Int J Environ Res Public Health. 2017;14(10):1229. doi:10.3390/ijerph14101229

10. Van Wijk EC, Landais LL, Harting J. Understanding the multitude of barriers that prevent smokers in lower socioeconomic groups from accessing smoking cessation support: A literature review. Prev Med. 2019;123:143151. doi:10.1016/j.ypmed.2019.03.029

11. Bryant J, Bonevski B, Paul C, McElduff P, Attia J. A systematic review and meta-analysis of the effectiveness of behavioural smoking cessation interventions in selected disadvantaged groups. Addiction. 2011;106(9):15681585. doi:10.1111/j.1360-0443.2011.03467.x

12. Hill S, Amos A, Clifford D, Platt S. Impact of tobacco control interventions on socioeconomic inequalities in smoking: review of the evidence. Tob Control. 2014;23(e2):e89-e97. doi:10.1136/tobaccocontrol-2013-051110

13. Crosby RA, Salazar LF, DiClemente RJ, Lang DL. Balancing rigor against the inherent limitations of investigating hard-to-reach populations. Health Educ Res. 2010;25(1):1-5. doi:10.1093/her/cyp062

14. Lee CS, Hayes RB, McQuaid EL, Borrelli B. Predictors of 
retention in smoking cessation treatment among Latino smokers in the Northeast United States. Health Educ Res. 2010;25(4):687-697. doi:10.1093/her/cyq010

15. Nevid JS, Javier RA, Moulton III JL. Factors predicting participant attrition in a community-based, culturally specific smoking-cessation program for Hispanic smokers. Health Psychol. 1996;15(3):226-229. doi:10.1037//0278-6133.15.3.226

16. Benson FE, Stronks K, Willemsen MC, Bogaerts NM, Nierkens V. Wanting to attend isn't just wanting to quit: why some disadvantaged smokers regularly attend smoking cessation behavioural therapy while others do not: a qualitative study. BMC Public Health. 2014;14:695. doi:10.1186/1471-2458-14-695

17. Roddy E, Antoniak M, Britton J, Molyneux A, Lewis S. Barriers and motivators to gaining access to smoking cessation services amongst deprived smokers-a qualitative study. BMC Health Serv Res. 2006;6(1):147. doi:10.1186/1472-6963-6-147

18. Frandsen M, Walters J, Ferguson SG. Exploring the viability of using online social media advertising as a recruitment method for smoking cessation clinical trials. Nicotine Tob Res. 2014;16(2):247-251. doi:10.1093/ntr/ntt157

19. McIntosh S, Ossip-Klein DJ, Spada J, Burton K. Recruitment strategies and success in a multicounty smoking cessation study. Nicotine Tob Res. 2000;2(3):281-284. doi:10.1080/14622200050147556

20. Henderson HJ, Memon A, Lawson K, Jacobs B, Koutsogeorgou E. What factors are important in smoking cessation amongst deprived communities? A qualitative study. Public Health. 2016;134:39-45. doi:10.1016/j.puhe.2016.01.014

21. RIVM. Rookvrij! Ook jij? [Smokefree! You too?]. https:// interventies.loketgezondleven.nl/leefstijlinterventies/ interventies-zoeken/1400743. Published 2019. Accessed June 22, 2019.

22. Van den Brand FA, Dohmen LM, Van Schayck OC, Nagelhout GE. 'Secretly, it's a competition': a qualitative study investigating what helped employees quit smoking during a workplace smoking cessation group training programme with incentives. BMJ Open. 2018;8(11):e023917. doi:10.1136/bmjopen-2018-023917

23. Richardson A, Allen JA, Xiao H, Vallone D. Effects of race/ethnicity and socioeconomic status on health information-seeking, confidence, and trust. J Health Care Poor Underserved. 2012;23(4):1477-1493. doi:10.1353/hpu.2012.0181

24. Stead LF, Koilpillai P, Fanshawe TR, Lancaster T. Combined pharmacotherapy and behavioural interventions for smoking cessation. Cochrane Database Syst Rev. 2012;10:CD008286. doi:10.1002/14651858.CD008286.pub2

25. Nagelhout G. Resultaten Wijkchallenge Samen Stoppen met Roken. Factsheet. Den Haag: Onderzoeksinstituut IVO; 2019. https://ivo.nl/publicaties/factsheetresultaten-wijkchallenge-samen-stoppen-met-roken/.
Accessed September 30, 2020.

26. RIVM. Voel je vrij! [Feel free!]. https://interventies. loketgezondleven.nl/leefstijlinterventies/interventieszoeken/1403240. Published 2018. Accessed September 30,2020 .

\section{ACKNOWLEDGEMENTS}

We thank Indigo Haaglanden (Ursula Dewkalie, Zeynep Sarikaya, Feroz Hansildaar, Renato van der Geld, Christel van Soelen) and Jellinek Utrecht (Marco Looije, Jaap Jamin, Tamara de Bruijn, Franca Hasenbos) for the recruitment of participants and the development and implementation of the smoking cessation program. We thank several students for their help with transcribing the interviews, in particular Allisha Biesheuvel, Arie Boven, Hiba Saleh, Lisa Dijkhoff, Vai van Ast, and Willemieke Ligtenberg.

\section{CONFLICTS OF INTEREST}

The authors have each completed and submitted an ICMJE form for disclosure of potential conflicts of interest. The authors declare that they have no competing interests, financial or otherwise, related to the current work. All authors report grants from Fonds NutsOhra, during the conduct of the study.

\section{FUNDING}

This study was supported by a grant from Fonds NutsOhra (\#102346).

\section{AUTHORS' CONTRIBUTIONS}

BVS, GJM, and WL performed the analyses and read all transcripts of the interviews. BvS and WL independently coded transcripts. GJM examined the coding framework and made suggestions for changes in consultation with WL. Disagreements between codes were discussed with BvS until consensus was reached.

\section{PROVENANCE AND PEER REVIEW}

Not commissioned; externally peer reviewed. 